Original Article

\title{
Enhancement of Flexural Strength of Two Nano-composites by Electron Beam Irradiation.
}

\author{
Mithra N. Hegde' ${ }^{1}$, Preethesh Shetty ${ }^{2}$, Raksha Bhat ${ }^{3}$, Tony Mathew ${ }^{4}$ \\ ${ }^{1} V i c e$ Dean, Dean of Faculty of Dental Sciences \& Head of the Department, ${ }^{2}$ Post-graduate Student, ${ }^{3,4}$ Assistant Professor, \\ Department of Conservative Dentistry and Endodontics, A.B. Shetty Memorial Institute of Dental Sciences, Nitte \\ University \\ *Corresponding Author : Preethesh Shetty, Post-graduate Student, Department of Conservative Dentistry and Endodontics, A. B. Shetty \\ Memorial Institute of dental Sciences, Nitte University, Deralakatte, M angalore - 575 018, Karnataka. \\ E-mail: preethesh_shetty@yahoo.co.in
}

$\begin{array}{lr}\text { Received } & : 05.06 .2016 \\ \text { Review Completed }: 12.10 .2016 \\ \text { Accepted } \quad: 04.11 .2016\end{array}$

Keywords : Flexural strength, nanocomposite, electron beam irradiation, Filtex

\begin{tabular}{|c|}
\hline Access this article online \\
\hline Quick Response Code \\
\hline
\end{tabular}

Abstract

Aim : The study aimed to assess and investigate the effect of electron beam irradiation on the flexural strength of two newer nanocomposites (FiltekZ350XT and Filtek Bulkfill)

Materials and Methods: Forty samples each of both the nanocomposites were prepared on rectangular bar shaped moulds $(25 * 2 * 2 \mathrm{~mm})$ according to ISO 4049 . The dosage of electron beam selected for the study were 2KGy, 4KGy and 10KGy. The forty specimens were divided into four groups based on the radiation doses; group I: non radiated, group II: 2KGy, group II : 4 KGy, group II : 10KGy with ten samples in each group. The samples were subjected to a 3point bend test on a universal uniaxial servo mechanical testing machine.

Results: The data was statistically analyzed using One way Anova analysis. Analysis demonstrated that Filtek Z350XT had better flexural strength than Filtek Bulkfill ( $P \varangle 0.001)$. The flexural strength of the composites increased with the dose of electron beam irradiation.

Conclusion: Within the limitations of the study, it can be concluded that the electron beam irradiation of the nanocomposites can be used as a tool to enhance their mechanical properties.

\section{Introduction}

Replacement of the biological, functional and esthetic properties of sound tooth structure embodies the supreme goal of any dental restorative material ${ }^{1}$. Dental amalgam and gold alloy shave demonstrated the highest clinical success rates for more than 100 years, due to the similarities between their mechanical properties with those of the natural teeth ${ }^{2}$. Nevertheless, aesthetics portrays to be the chief disadvantage of these materials. The enigma of aesthetics in restorative materials has been resolved since the advent of resin composites. However, due to its inferior durability and strength, the use of composites waslimited ${ }^{3}$. Over the years, major developments have been undertaken to improvise the clinical performance of composites.

The necessity of functional demand of posterior restorations and the superior aesthetics required for anterior restorations has been met with the introduction of nanocomposites ${ }^{4}$. Nanocomposites encompass improved mechanical properties, which include superior compressive strength, diametrical tensile strength, fracture resistance, wear resistance, low polymerization shrinkage, high translucency, high polish retention and better aesthetics ${ }^{3,4}$.

Electron beam is a stream of electrons generated by heat, bombardment of charged atoms or particles, or strong electric fields. Cross linking by electron beam irradiation is an effective substitute to cross linking by chemical agents ${ }^{5}$ The cross linking of the polymers severely impedes the molecular movement, causing the polymer to be stable against heat. The primary effects of electron beam irradiation are chain scission, oxidation and increased 
unsaturation, based on the dose rate and the oxygen content in the exposed environment ${ }^{6}$.

The present study aimed to assess and investigate the effect of electron beam irradiation on the flexural strength of two nano-composites; Filtek Z350XT and Filtek Bulk fill in order to achieve enhanced flexural strength.

\section{Materials and M ethods}

The flexural strength of FiltekZ350XT and FiltekBulkfill was evaluated before and after electron beam irradiation.

The composition of the materials is given in the Table 1.

\section{Operative procedure}

Preparation and grouping of the specimens for flexural strength

A total of 80 samples; 40 samples each of two different composite materials having 10 specimens in each group were fabricated using customized bipartite brass mold measuring $25 \mathrm{~mm} \times 2 \mathrm{~mm} \times 2 \mathrm{~mm}$, according to ISO standard 4049.

\section{Preparation of the specimens}

The composite resins used for this study were two nanocomposites, FiltekZ350XT and FiltekBulkfill, Posterior composite.

The composite resins were placed in mould. The composites were covered with a mylar strip. A glass slide (1mm thick) is then placed over composites and pressure is applied to accommodate the material into the mold and to extrude excess material. After removing the glass slide, the composites were then cured from the top and bottom surfaces through the mylar strip as per the manufactures instructions using the LED light curing unit. The specimens were taken out of the brass mould and light cured in the middle of the specimen at opposing sides. The study was performed in controlled temperature by keeping it in a distilled water bath for $24 \mathrm{~h}$ at $37^{\circ} \mathrm{C}$.

\section{Groups}

In total, 80 specimens were fabricated and divided into 4 groups based on the irradiation dose.

Group $1=$ non radiated
Group II=2kGy Group III=4kGy Group IV=10 kGy

The fabricated samples were subjected to their respective doses of radiation.

\section{Standardization of dose}

The materials were radiated using an $8 \mathrm{M} \mathrm{eVM}$ icrotron at $M$ icrotron Centre, M angalore University, M angalore, India. The doses indicated for the study were 2kGy, 4 kGy and 10 kGy.

\section{Testing procedure}

All specimens were subjected to the 3 Point bend test on a universal uniaxial servo mechanical testing machine (Model 33 R 4467; Instron Corp; 3M ESPE, Bangalore) individually and subjected to flexural strength analysis at crosshead speed of

$0.75 \mathrm{~mm} / \mathrm{min}$. [model no. 4206].

Table 1 : Composition of the Nanocomposites analyzed in the study.

\begin{tabular}{|l|l|}
\hline M aterial & Composition \\
\hline FiltekZ350XT (3M ESPE, & The resin matrix : Bis-GM A, UDM A, \\
St.Paul, M inessota, USA) & TEGDM A and \\
The filler : Co m A & $\begin{array}{l}\text { aggregated zirconia/silica cluster } \\
\text { with pri- mary particle size (5-20 } \\
\text { nm), and nonagglomerated silica } \\
\text { filler (20 nm). }\end{array}$ \\
\hline FILTEK BULK FILL, Posterior & $\begin{array}{l}\text { The resinmatrix: AUDM A, UDMA, } \\
\text { Restorative (3M ESPE, } \\
\text { St.Paul, M inessota, USA) } \\
\text { dodecane-DM A. }\end{array}$ \\
$\begin{array}{l}\text { The filler: Non-agglomerated } \\
\text { /non-aggregated 20nm silicafiller, a } \\
\text { Non-agglomerated/non-aggregated } \\
4 \text { to 11 nm zirconia filler, an } \\
\text { aggregated zirconia/silica cluster } \\
\text { filler (20nm silica and 4 to 11 nm } \\
\text { zirconia particles), and a ytterbium } \\
\text { trifluoride filler consisting of } \\
\text { agglomerate 100 nm particles. } \\
\text { (Khalil Yousef, 2015) }\end{array}$ \\
\hline
\end{tabular}

\section{Results}

The data obtained from the present study was subjected to statistical analysis using one-way ANOVA and inter group comparison is done using student t test.

The flexural strength of experimental groups was compared with one way ANOVA test, $p$ value $<0.001$ was obtained which indicates highly statistically significant 
ANOVA.

\begin{tabular}{|l|l|l|l|l|l|l|l|}
\hline \multicolumn{2}{|l|}{ Group } & N & Mean & SD & M inimum & Maximum & $\begin{array}{c}\text { ANOVA } \\
\text { p value }\end{array}$ \\
\hline \multirow{2}{*}{1} & Control & 10 & 172.05 & 2.93 & 167.87 & 176.23 & \multirow{2}{*}{$0.001^{*}$} \\
\cline { 2 - 7 } & 2 kGy & 10 & 285.45 & 3.48 & 280.34 & 291.36 & \\
\cline { 2 - 7 } & 4 kGy & 10 & 341.92 & 5.79 & 334.52 & 353.21 & \\
\cline { 2 - 7 } & 10 kGy & 10 & 388.60 & 11.13 & 375.63 & 407.15 & \\
\hline 2 & Control & 10 & 155.26 & 2.54 & 151.32 & 158.24 & \multirow{2}{*}{$0.001^{*}$} \\
\cline { 2 - 7 } & 2 kGy & 10 & 206.74 & 4.75 & 198.27 & 214.53 & \\
\cline { 2 - 6 } & 4 kGy & 10 & 256.87 & 5.99 & 248.24 & 264.32 & \\
\cline { 2 - 6 } & 10 kGy & 10 & 311.85 & 4.96 & 303.67 & 318.12 & \\
\hline
\end{tabular}

difference between tested materials [Table2]. The Comparison off lexural strength between FiltekZ350 XT and FiltekBulkfill at different doses of radiation is depicted in Graph 1.

\section{Discussion}

The increasing demand for aesthetic dentistry during the last few decades has led to the advent of composite resin materials for direct restorations. The latest innovations and developments in the field have led to composite resins with improved physical and mechanical properties, esthetics and durability. ${ }^{7,8}$ The introduction of nano-filler technology, which involves combination of nano-metricparticles and nano clusters in a conventional resinmatrix, is the latest advance mentin the field ${ }^{3}$. These composites have demonstrated superior mechanical properties and are indicated for posterior restorations due to their high strength as well as anterior restorations due to their high esthetic properties. The mechanical properties of a material depict its response to loading. In most of the clinical situations, composite resin restorations undergo a considerable amount of flexuralstress ${ }^{9}$. Hence, ideal restorative materials are required to avoid deformation by masticatory stresses, which damage the marginal seal of the restoration ${ }^{10}$. Filtek Z350XT is a nanocomposite with a combination of nanomer sized particles to the nano cluster formulations that helps decrease the interstitial spacing of the filler particles. This assures enhanced filler loading, superior physical properties when compared to the composites comprising of only nanoclusters.

Filtek Bulk Fill Posterior Restorative material is a visible, light-activated restorative composite. The fillers are a combination of a non-agglomerated/non-aggregated 20 $\mathrm{nm}$ silicafiller, a non-agglomerated/ non-aggregated 4 to 11 nmzirconia filler, an aggregated zirconia/ silica cluster filler and aytterbiumtri fluoride filler consisting of agglomerate

$100 \mathrm{~nm}$ particles. This bulk fill material provides excellent strength and low wear for durability.

The electron beam irradiation has been proven to be an efficient method to structurally modify the materials, ${ }^{11,}{ }^{12}$. Earlier studies have advocated the enhancement of mechanical properties on the compressive and flexural strengths of resin modified glass ionomer cement, rely $x$ luting cement and nanocomposites after irradiation ${ }^{13,14,15}$.

In the present study, the flexural strengths of two different composites were evaluated before and after irradiation with three doses of radiation 2kGy, 4kGy and 10kGy. The Flexural strength of Filtex Z350 XT before radiation was $172.5 \mathrm{MPa}$. The flexural strength of FiltexZ350XT after irradiation with $2 \mathrm{kGy}, 4 \mathrm{kGy}$ and $10 \mathrm{kGy}$ was found to be $285.45,341.92$ and 388.6 respectively. The $p$ value was statistically significant $(p<0.001)$ (Table 2$)$. Flexural strength of Filtek Bulfill before radiation was155.26. Flexural strength of Filtek Bulfill after irradiation with 2kGy, 4kGy and 10kGy was found to be 206.74, 256.87 and 311. 85 respectively. The $P$ value was statistically significant $(p \varangle 0.001)$ (Table 2). A comparison of flexural strength between Filtex Z350 XT and Filtek Bulfill before and after radiation was also analyzed, where Filter Z350 XT showed better results (Graph 1).

The results advocated that the flexural strengths of the radiated samples were statistically significant as compared to the control samples. A positive correlation was found between the increase in the dosage of radiation with the increase in the flexural strength. The increase in flexural strength after electron beam irradiation can be attributed to the cross- linking and polymerization.

Cross-linking constitutes linking together long chains of polymers which in turn increases the molecular mass of the polymer. In this process, the chemical structure of the 
polymer gets altered. During the process of irradiation, free radicals are released which recombine for ming the cross links ${ }^{5,6}$. The degree of cross-linking varies depending upon the polymerization reaction and the radiation dose. The major advantage of cross-linking from electron beam irradiation is that the degree of cross linking is controlled by the amount of dosage of radiation ${ }^{16}$.

The increased flexural strength may also be attributed to the polymerization reaction. Polymerization reaction is basically a chain reaction, which can be, explains as the number of double carbon links present in the monomers getting converted into single links to form the polymeric chain during the polymerization process called the degree

\section{References}

1. Mithra N Hedge, Priyadarshini Hegde, Shruthi Bhandary, Deepika K An evalution of compressive strength of newer nanocomposite: An in vitro study. JCD 2011. 14(1):36-39

2. LuH, LeeYK, OguriM, Powers) M. Properties of adentalres in composite with a spherical inorganic filler. Oper Dent 2006; 31:734-40.

3. Mitra SB, Dong WU, Holmes BN. An application of nanotechnology in advanced dental materials. J Am Dent Assoc2003; 134:1382-90

4. MosznerN, Klapdohr S. Nanotechnology for dental composites. Int J Nanotechnol2004; 1:130-41.

5. Vallat, M.F., Marouni, S.Perraud, S. And Mendoza Patlan, N. (2005) Cross linked Blends and Coextruded Films by Electron Beam. Nucl. Instrum. Methods B236, 141-144.

6. Pascu, M., Vasile, C. Andgheorghiu, M. (2003) M odification of Polymer Blend Properties by Argon Plasma/Electron Beam Treatment: Surface Properties. Mater. Chem. Phys., 80, 548-554.

7. M ota EG, Oshima HM, Burnett LH Jr, Pires LA, Rosa RS. Evaluation of diametrical tensile strength and knoopmicro hardness of five nano filled composites in dentin and enamel shades. Stomatologija 2006; 8:67-9.

8. Ruddell DE, M aloney M M , Thompson JY. Effect of novel filler particles on the mechanical properties of dental composites. Dent M ater 2002; 18:72-80.

9. SN Garapati, P Raturi, D Shetty, KV Srikanth. An in vitro evaluation of diametral tensile strength and flexural strength of nanocomposite vshy brid and minifill composites cured with different light sources (QTH vsLED). The journal of contemporary dental practice.2013.14 (1), 84

10. Palin WM, Fleming G], Marquis PM. The reliability of standardized flexure strength testing procedures for a light-activated resin-based composite. Dent M ater. 2005; 21(10):911-9.

11. Greer, R.W., Wilkes, G.L. Apparent reversal of physical aging by electron beam irradiation-further investigations. Polymer. 1998; 39: 4205-4210.

12. Charles by, A.,Ross, M. Effect of high-energy radiation on longchainpolymers. Nature. 1953; 171:167. of conversion ${ }^{17,18}$. The reactions of monomers in order to form a polymer is known to have an important effect on the physical and mechanical properties of composites resins $^{19,20,21,22}$

\section{Conclusion}

Nanotechnology has brought about the advent a restorative material with increased polish ability, as well as excellent mechanical properties suitable for high stress bearing restorations. However, further in-vitro studies can be carried out to improvise on the mechanical behavior of Nano filled composites and in-vitro studies to determine their clinical performance.

13. Hegde M N, Shabin S, Hegde ND, Kumari S, Sanjeev G, Shetty S. Electron beam irradiation effect on flexural strength and modulus of elasticity of resin modified glass ionomer luting agent. International Journal of Biology and Medical Research. 2013;4(4):3690-3694.

14. Shabin S, Hegde M N, Hegde ND, Kumari S, Sanjeev S, Shetty Shilpa. Electron beam irradiation effect on compressive strength of resin modified glass ionomer luting agent. Journal of Applicable Chemistry. 2013;2(6):1589-1594.

15. M ithra N. Hegde, Shilpa S. Shetty, Nidarsh D. Hegde, Suchetha Kumari, Ganesh Sanjeev and Amit Patodiya. Effect of Electron Beam Irradiation on Flexural Strength of Two Nanocomposites-aninvitro Study. British Journal of M edicine \& M edical Research 4(28): 4654-4664, 2014

16. ParksLA. Radiation Crosslinking of Polymers. Sterigenics advanced applications February 2, 2010. Available: http:// www.sterigenics. com/advanced.htm.

17. Obici AC, Sinhoreti MA, Correr Sobrinho L, deGoes MF, ConsaniS. Evaluation of depth of cureandknoop hardness in a dental composite photo activated using different methods. Brazilian Dental Journal. 2004;15(3):199-203.

18. FerracaneJ L. Correlation between hardness and degree of conversion during the setting reaction of unfilled dental restorative resins. Dental Materials. 1985;1(1):11-14.

19. AsmussenE, PeutzfeldtA. Two-step curing: influence on conversion and softening of a dental polymer. Dental M aterials. 2003;19(6):46670.7 .

20. FerracaneJ $L$, GreenerEH. The effect of resin formulation on the degree of conversion and mechanical properties of dental restorative resins. Journal of Biomedical M aterials Research. 1986;20(1):121-31.8.

21) NomotoR, UchidaK, HirasawaT. Effect of light intensity on polymerization of light- cured composite resins. Dental Materials Journal. 1994;13(2):198-205.

22) SakaguchiRL, BergeHX. Reduced light energy density decreases postgel contraction while maintaining degree of conversion in composites. Journal of Dentistry. 1998;26(8):695-700. 